\title{
PRODUÇÃO E DISSEMINAÇÃO DA INFORMAÇÃO ESTATÍSTICA agências estaduais no Brasil
}

\author{
Paulo de Martino Jannuzzi
}

Luciana de Souza Gracioso

\begin{abstract}
Resumo: Discussão sobre os resultados de uma pesquisa que procurou caracterizar a produção e a política de disseminação de informações das agências estaduais de estatística. Em meio às dificuldades operacionais e orçamentárias, essas agências vêm procurando atender às demandas da sociedade e do planejamento público, com a ampliação do escopo temático investigado, disponibilização a informação estatística em suportes mais flexíveis e adoção de práticas mais ativas na disseminação de seus produtos.

Palavras-chave: disseminação da informação; Sistema Estatístico Nacional; planejamento público.
\end{abstract}

\begin{abstract}
Under discussion in this article are the results of a study aimed at evaluating the performance of public statistical services in producing and disseminating information. Despite operational and budgetary limitations, these entities seek to meet both the demands of the public and the needs of policy makers through a wider thematic scope, more flexible presentation of statistical information, and the adoption of more proactive dissemination practices.

Key words: dissemination of information; National Statistics System; public planning.
\end{abstract}

A informação estatística é um insumo fundamental para planejamento e formulação de políticas e estratégias no mundo contemporâneo. No ambiente de incertezas e de rápidas transformações que caracterizam o momento atual, não há como uma organização privada ou pública antecipar de modo consistente os cenários futuros, estabelecer metas realistas, definir planos de contingência, ou, enfim, tomar decisões em bases mais técnicas, em qualquer escala, sem o emprego e a análise das estatísticas econômicas, sociais e demográficas disponíveis para os domínios geográficos de atuação da organização. As estatísticas públicas permitem às empresas fazer estimativas conjunturais de expansão ou contração de consumo, descobrir oportunidades locacionais para instalação ou exploração comercial, avaliar as taxas de crescimento de mercados. No setor público e na sociedade civil, esferas de poder de interesse particular neste projeto, a informação estatística constitui, ademais de recurso básico e estratégico para a elaboração de diagnósticos sociais e econômicos ou dimensionamento do público-alvo de planos e políticas, um instrumento de controle societal do Estado.

No caso brasileiro, o uso da informação estatística no planejamento público e para controle societal data de um passado não muito distante. Em primeiro lugar, é preciso assinalar que a produção de um conjunto amplo de estatísticas públicas não tem mais do que 30 anos no país, ainda que as bases institucionais para implantação de um Sistema Estatístico Nacional já tivessem sido criadas nos anos 30, no Governo Getúlio Vargas, com a fundação do Instituto Brasileiro de Geografia e Estatística (IBGE). Desde então, o Sistema de Estatísticas Públicas brasileiro apresentou uma expressiva evolução qualitativa e quantitativa, especialmente a partir dos anos 60 quando o IBGE começou a diversificar seu portfólio de pesquisas, apoiado por agências multilaterais (Divisão Estatística das Nações Unidas e Bureau of Census Americano). Assim, além dos Censos Demográficos elaborados regularmente desde 1940, passou-se a implantar pesquisas domiciliares sistemáticas para monitoramento de tendências demográficas e características socioeconômicas da população, pesquisas contínuas para acompanhamento do mercado de trabalho, painéis de avaliação conjuntural da indústria, comércio, serviços e agropecuária, além de melhorar o processamento das informações provenientes do registro civil e dos registros administrativos dos ministérios (Jannuzzi, 1995). 
Com a criação de um corpo qualificado de técnicos na burocracia federal ao final da década de 60 e a valorização das atividades de planejamento nos ministérios, a informação estatística passou a ser elemento imprescindível para a formulação de políticas nacionais de desenvolvimento econômico e social. A criação do Instituto de Pesquisa Econômica Aplicada (Ipea) em 1964 é um fato emblemático nesse sentido. Na década seguinte, nos anos 70, os governos dos Estados mais desenvolvidos também começam a estruturar suas agências ligadas a produção, compilação e análise de estatísticas para subsidiar a definição de políticas nas diversas áreas, sobretudo na de educação e saúde.

Com a redemocratização das instâncias políticas, avanço da descentralização tributária e a institucionalização do processo de planejamento público em âmbito local no país em meados da década de 80 , as estatísticas públicas passaram a ser empregadas de forma mais ampla e tecnicamente mais responsável na formulação de políticas na esfera municipal. Para fundamentar a elaboração de planos diretores de desenvolvimento urbano e planos plurianuais de investimentos, para permitir a avaliação dos impactos ambientais decorrentes da criação de grandes projetos, para justificar o repasse de verbas federais para implementação de programas sociais ou ainda pela necessidade de disponibilizar equipamentos ou serviços sociais para públicos específicos, por exigência legal (para portadores de deficiência, por exemplo) ou por pressão política da sociedade local (melhoria dos serviços de transporte urbano, por exemplo), diversos municípios de médio e grande portes passaram a demandar com maior freqüência uma série de indicadores sociodemográficos e econômicos às agências estatísticas e outras instituições ligadas ao planejamento público.

O uso da informação estatística como instrumento de controle societal do Estado, em suas diversas esferas, é algo ainda mais recente que a estruturação do sistema de produção e disseminação das estatísticas e o uso das mesmas no planejamento público. Como discutido em Jannuzzi (2001), embora já fossem usadas há um bom tempo nas universidades para elaboração de estudos acadêmicos e relatórios sociais de divulgação mais ampla, as estatísticas públicas passaram a constituir material de consulta periódica de jornalistas, sindicatos e outras entidades da sociedade civil no Brasil há menos de dez anos. É na década de 90 que a taxa de mortalidade infantil, taxa de analfabetismo, nível de desemprego, grau de indigência e pobreza, Índice de Desenvolvimento Humano passaram a ser corriqueiramente citados nos jornais, na mídia eletrônica, nos debates políticos. Finalmente, depois de muito tempo confinadas às esferas técnicas e acadêmicas dos órgãos de Planejamento Público e universidades, as estatísticas públicas passaram a integrar o vocabulário corrente dos agentes políticos responsáveis, em última instância, pela definição das prioridades das políticas sociais e alocação dos recursos públicos. A informação estatística, agora facilmente acessível através da Internet, deixou de figurar apenas nos diagnósticos e relatórios governamentais, ganhando um papel mais relevante nas arenas de discussão político-social da sociedade brasileira, na avaliação dos avanços ou retrocessos nas condições de vida da população, no apontamento da eficácia ou ineficácia das políticas públicas ou na defesa técnica quanto às prioridades sociais a atender.

Em que pesem os avanços obtidos na produção e disseminação das estatísticas públicas nestes últimos 30 anos, há certamente muitas lacunas e problemas estruturais a resolver, que dificultam de forma expressiva o uso final destas informações para o planejamento público e controle societal do Estado. Entre os técnicos de planejamento municipal, por exemplo, têm sido constantes as queixas com relação à disponibilização das estatísticas. No documento intitulado Informação para uma sociedade democrática: por uma política nacional de produção e disseminação de informações sociais, econômicas e territoriais, elaborado por várias sociedades científicas na última Conferência Nacional de Estatística (Confest) no Rio de Janeiro em 1996, os municípios e sua realidade local foram apontados como as áreas mais carentes de dados do Sistema Estatístico Nacional. Outros pesquisadores e técnicos têm apontado sistematicamente a lacuna na disponibilidade de informação estatística sobre algumas temáticas, como meio ambiente, uso do tempo, qualidade de vida, pobreza, etc. (Prosérpio, 1994; Jannuzzi, 1998).

Também no Livro Verde do projeto do Ministério da Ciência e Tecnologia Sociedade da informação no Brasil há referências sobre a necessidade de produção de "novos conteúdos" e "informações públicas", que, em alguma medida, rebatem-se na pauta de serviços e produtos das agências estatísticas (MCT, 2000). Há acervos consideráveis de informação estatística que podem ser "re-trabalhados" para atender à necessidade preconizada pelos autores do livro para a disseminação pela Internet de "conteúdos" sobre a identidade cultural brasileira, sobre as atividades governamentais realizadas, sobre a produção nacional em Ciência e Tecnologia, sobre especificidades regionais. 
De fato, até pouco tempo atrás, como bem caracteriza Senra (1994), os institutos de estatística trabalhavam na crença da validade da Lei de Say, de que toda oferta acabava criando sua própria demanda. O importante era, pois, produzir dados através de pesquisas e disseminá-los por publicações e planos tabulares definidos quando das primeiras edições do levantamento primário. Imaginava-se que tais documentos eram mais que suficientes para a maioria dos usuários. Demandas específicas poderiam ser atendidas, no seu devido tempo e importância. A disseminação dos dados era praticamente reativa: o atendimento, lento e não-democrático; a base de dados, subutilizada. Vivia-se o paradoxo da escassez na abundância, outra tirada muito espirituosa e correta do autor. O próprio autor reconhece que esse quadro vem mudando, à medida que os institutos começam a modificar sua política de disseminação de informações no sentido de torná-la mais atenta às necessidades do usuário demandante e mais pró-ativa na concepção, oferta e distribuição de novos produtos.

Assim, em outras tantas reavaliações que a virada do século e os 500 anos de descobrimento têm ensejado, também parece oportuno fazer um balanço, ou melhor, uma releitura do processo de consolidação do Sistema de Produção e Disseminação de Informações Estatísticas no país e da sua importância na institucionalização do planejamento público em bases mais técnicas, nas três esferas de governo. Foi nessa perspectiva que se iniciou o projeto de pesquisa "A produção, a disseminação e o uso da informação estatística no Brasil: características atuais, avanços e desafios", com a finalidade de analisar as características atuais do Sistema Nacional de Estatísticas Públicas, discutindo seus avanços e continuidades ao longo das últimas décadas em termos da produção das estatísticas, da sua disseminação para a sociedade e do uso dessas estatísticas por parte dos formuladores de políticas públicas.

Este trabalho é um dos primeiros resultados do referido projeto, e está focalizado mais especificamente na apresentação dos esforços de produção e disseminação dos institutos estaduais de planejamento e estatística no país. Através de um levantamento estruturado realizado nos institutos estaduais em dezembro de 2001, identificou-se o escopo temático das informações estatísticas produzidas e compiladas por eles, o elenco de informações disponibilizadas nas suas principais publicações impressas, pela Internet e por outras mídias, as características da demanda e de seus principais usuários, além das suas políticas e práticas de disseminação das estatísticas pro-

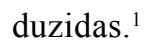

No presente artigo expõem-se, inicialmente, os aspectos metodológicos do levantamento realizado em agências estaduais de estatística, abordando os procedimentos de aplicação e construção do instrumento de pesquisa. Em seguida discutem-se os resultados do levantamento, isto é, os aspectos relacionados à produção e, finalmente, aqueles afeitos ao acesso e disseminação das estatísticas estaduais.

\section{A PESQUISA EM INSTITUTOS ESTADUAIS DE PLANEJAMENTO E ESTATÍSTICA}

Diferentemente de outros países latino-americanos, no Brasil as estatísticas sociais, econômicas e demográficas são produzidas, compiladas e disseminadas por diferentes agências, na esfera federal ou na estadual. Através de uma rede capilarizada pelo território nacional, com unidades estaduais e agências municipais, o Instituto Brasileiro de Geografia e Estatística (IBGE) cumpre seu papel de agente coordenador do Sistema de Produção e Disseminação de Estatísticas Públicas, como produtor de dados primários, compilador de informação proveniente de ministérios e como agente disseminador de estatísticas. As agências estaduais de estatística também compilam uma ampla variedade de dados administrativos produzidos pelas secretarias de Estado e, em alguns casos, também produzem dados primários provenientes de pesquisas amostrais. Alguns ministérios, secretarias estaduais e, em menor escala, alguns municípios, também têm órgãos encarregados da produção ou organização de seus dados administrativos.

Essa diversidade de sujeitos impôs, portanto, a necessidade de identificação dos principais agentes integrantes do Sistema Nacional de Estatísticas Públicas nos Estados brasileiros, cuja relação figura no Apêndice 1 juntamente com seus respectivos endereços e sites na Internet ${ }^{2}$ (quando existentes).

Como era de se esperar, os processos de produção, compilação e disseminação das estatísticas públicas nos Estados estão sob a responsabilidade das Secretarias Estaduais de Planejamento (Seplans) ou de órgãos estaduais específicos a elas vinculados - na forma de fundações ou autarquias - não pertencentes à estrutura da Administração Direta Estadual. Chama a atenção, contudo, que os institutos de pesquisa e planejamento já constituem a maioria entre esses agentes: em 14 das 27 unidades de federação há órgãos específicos para tratamento da informação estatística. 
Tal forma de organização é, certamente, uma evolução natural do processo de institucionalização das atividades de planejamento em nível estadual. O reconhecimento do papel estratégico da informação estatística, na formulação de programas públicos nas diversas secretarias e no acompanhamento de metas de governo, acaba por impor a necessidade de contratação de pessoal técnico e sua organização em departamentos específicos para lidar com a informação nas suas diversas áreas temáticas (demográfica, social, econômica, ambiental) e estágios de processamento (coleta, compilação, armazenamento, análise e disseminação). Também contribuem para esse processo de institucionalização da produção e disseminação da informação estatística em órgãos estaduais específicos as próprias demandas de informação por parte da sociedade civil, imprensa, sindicatos, partidos políticos e empresas, no cumprimento de suas atribuições e atividades de fiscalização, monitoramento ou planejamento.

É, pois, alvissareiro constatar que não são apenas os Estados do Sudeste e Sul que dispõem de institutos específicos para o tratamento da informação estatística. Essa modalidade de organização vem gradativamente sendo adotada pelo país afora, mas em menor intensidade nos Estados da Região Norte. Vale observar, contudo, que no contexto de ajuste do setor público nos últimos dez anos, algumas instituições de tradição na área - como a Codeplan - acabaram tendo suas atividades severamente comprometidas ou mesmo acabaram sendo extintas, sem que suas funções tenham sido realocadas adequadamente - e de forma centralizada - em outro órgão ou departamento na administração estadual. Parece um contra-senso extinguir essas agências ou impor-lhes restrições asfixiantes em seus orçamentos - como se viu inclusive nos Estados mais desenvolvidos - quando a informação estatística se torna cada vez mais importante para gestão eficiente dos recursos financeiros do Estado, das políticas públicas, dos programas sociais, como bem observam Guizzardi e Conti (2001).

Com a identificação dos agentes estaduais que lidam com a informação estatística passou-se, então, em dezembro de 2001, à etapa de remessa de um questionário estruturado autopreenchido para cada instituição, com o objetivo de levantar o escopo temático dos dados produzidos ou compilados, o perfil dos usuários e da intensidade da demanda de informação, os produtos e políticas de disseminação das estatísticas tratadas. Para garantir maior adesão à pesquisa, divulgou-se a intenção de realizá-la em uma das sessões do Encontro da Anipes - Associação Nacional dos Institutos de Planejamento, Pesquisa e Es- tatística - realizado no Rio de Janeiro em novembro de 2001. Além disso, foi encaminhado um envelope selado para envio do questionário preenchido.

Na primeira parte do questionário solicitou-se que fossem assinaladas as áreas temáticas de informação estatística produzidas ou compiladas pela instituição, indicando se eram de dados primários (dados coletados diretamente em cartórios, empresas ou domicílios) ou secundários (obtidos em outros órgãos públicos e secretarias). Também se solicitou que fossem assinalados os formatos de disseminação dessas informações, considerando os suportes digitais (Internet), publicação impressa ou multimídia (CDROM, vídeo). A terminologia empregada, para essa questão específica, foi desenvolvida a partir de uma ampla pesquisa bibliográfica, apoiando-se sobretudo no Catálogo do IBGE (IBGE, 2000), em artigo publicado por Allevato (1995) e no Relatório Sistema de informações das Instituições Públicas de Pesquisas (Anipes, 2001). Outras estruturas de organização terminológica foram analisadas como o Tesauro ${ }^{3}$ desenvolvido pelo SEADE (Fundação Sistema Estadual de Análise de Dados), as Listas de Cabeçalho e Assunto do Pais (Public Affairs Information Service desenvolvido pela OCLC - On-line Computer Library Center) e Tabelas de Áreas de Conhecimento desenvolvidas pelo CNPq (Conselho Nacional de Desenvolvimento Científico e Tecnológico).

Em Gracioso e Jannuzzi (2002) apresentam-se os termos pesquisados e estruturados como uma possível proposta para indexação e a recuperação da informação estatística tratada no âmbito das agências estaduais. Em síntese, nessa proposta, as estatísticas públicas foram estruturadas em categorias que implicam estabelecer níveis de assunto em obediência a uma organização hierárquica. O nome de uma categoria é o nome de uma classe de assunto constituída de subassuntos. Nesse sentido, os termos selecionados foram organizados segundo três temas gerais (econômico, social e meio ambiente) e 15 categorias (população, trabalho e rendimento, educação e outros) que, por sua vez, foram divididas em subcategorias (natalidade, mortalidade, óbitos fetais, por exemplo). O conjunto de termos apresentados organiza-se parcialmente conforme um Sistema de Classificação de Informação, não podendo ser designado como um Tesauro por não considerar aspectos relevantes de tal linguagem documentária, como as notas de aplicação, indicação de termo preferido, indicação de termo não preferido, termo genérico, termo específico e termo associado. No entanto, designar a estrutura terminológica desenvolvida unicamente como um Siste- 
ma de Classificação de Informação, também não seria viável visto que tais sistemas são organizados não apenas segundo a descrição temática e hierárquica de conceitos, como também se atribui a eles componentes numéricos e simbólicos para que sirvam efetivamente como um instrumento de tratamento de informação. A estrutura desenvolvida não inclui tais componentes; sua relevância como instrumento de tratamento e recuperação da informação está em reunir de maneira objetiva, clara e precisa, os termos mais significativos que retratam as Estatísticas Públicas.
$\mathrm{Na}$ segunda parte do questionário foram solicitadas informações sobre pessoal técnico, características da demanda e política de disseminação das estatísticas tratadas. Coletaram-se, então, dados sobre quantidade de recursos humanos alocados na disseminação das estatísticas segundo a natureza funcional (bibliotecários, analistas, técnicos de informática, auxiliares de biblioteca, estagiários e outros), volume de consulta ao acervo e site na Internet, freqüência de consulta às publicações, perfil do usuário demandante de estatísticas e as práticas de venda subsidiada e distribuição de produtos para bibliotecas e órgãos públicos.

\section{QUADRO 1}

Órgãos Estaduais Envolvidos na Produção e Disseminação das Estatísticas Públicas e Situação de Preenchimento do Questionário Brasil - Dez./2001-Abr./2002

\begin{tabular}{|c|c|c|}
\hline Unidades da Federação & Instituição & Situação de Preenchimento \\
\hline Acre & Secretaria de Estado de Planejamento e Coordenação & Recebido diretamente em jan./02 \\
\hline Amazonas & $\begin{array}{l}\text { Secretaria Estadual de Administração, Recursos Humanos e Previdência - } \\
\text { Coordenação de Planejamento }\end{array}$ & Não recebido \\
\hline Amapá & $\begin{array}{l}\text { Secretaria do Planejamento e Coordenação Geral - } \\
\text { Departamento de Estatística e Informação }\end{array}$ & Não recebido \\
\hline Pará & Secretaria Executiva de Planejamento e Coordenação Geral & Recebido diretamente em abr./02 \\
\hline Rondônia & Secretaria de Estado do Planejamento, Coordenação Geral e Administração & Recebido diretamente em abr./02 \\
\hline Roraima & Secretaria de Planejamento & Recebido diretamente em mar./02 \\
\hline Tocantins & Secretaria do Planejamento de Tocantins & Recebido diretamente em abr./02 \\
\hline Alagoas & Secretaria de Estado do Planejamento & Recebido diretamente em abr./02 \\
\hline Bahia & Superintendência de Estudos Econômicos e Sociais da Bahia & Recebido diretamente em jan./02 \\
\hline Ceará & Fundação Instituto de Pesquisa e Informação do Ceará & Recebido diretamente em jan./02 \\
\hline Maranhão & Gerência de Planejamento e Desenvolvimento Econômico & Não recebido \\
\hline Pernambuco & Instituto de Planejamento de Pernambuco & Recebido diretamente em jan./02 \\
\hline Piauí & Fundação Centro de Pesquisas Econômicas e Sociais do Piauí & Não recebido \\
\hline Paraíba & Instituto de Desenvolvimento Municipal e Estadual da Paraíba & Recebido diretamente em abr./02 \\
\hline Rio Grande do Norte & $\begin{array}{l}\text { Fundação Instituto de Desenvolvimento Econômico e } \\
\text { Meio Ambiente do Rio Grande do Norte }\end{array}$ & Recebido diretamente em fev./02 \\
\hline Sergipe & Secretaria de Estado do Planejamento e da Ciência e Tecnologia & Preenchido especialista em jan./02 \\
\hline Espírito Santo & Instituto de Apoio à Pesquisa e ao Desenvolvimento Jones dos Santos Neves & Recebido diretamente em fev./02 \\
\hline Minas Gerais & Fundação João Pinheiro & Recebido diretamente em abr./02 \\
\hline Rio de Janeiro & Centro de Informação e Dados do Rio de Janeiro & Recebido diretamente em jan./02 \\
\hline São Paulo & Fundação Sistema Estadual de Análise de Dados & Recebido diretamente em jan./02 \\
\hline Paraná & Instituto Paranaense de Desenvolvimento Econômico e Social & Recebido diretamente em jan./02 \\
\hline Rio Grande do Sul & Fundação de Economia e Estatística & Recebido diretamente em jan./02 \\
\hline Santa Catarina & Secretaria de Estado do Desenvolvimento Econômico e Integração ao Mercosul & Recebido diretamente em jan./02 \\
\hline Distrito Federal & Secretaria de Desenvolvimento Urbano e Habitação & Recebido diretamente em fev./02 \\
\hline Goiás & Superintendência de Estatística, Pesquisa e Informação & Recebido diretamente em abr./02 \\
\hline Mato Grosso do Sul & Instituto de Estudos e Planejamentos de Mato Grosso do Sul & Recebido diretamente em fev./02 \\
\hline Mato Grosso & Secretaria do Estado de Planejamento e Coordenação Geral & Recebido diretamente em fev./02 \\
\hline
\end{tabular}

Fonte: Jannuzzi e Gracioso (2002) 
Em que pese o esforço de coleta de dados na totalidade das agências estaduais de estatística - pela remessa de até quatro vezes o questionário e contatos pessoais de dezembro de 2001 a abril de 2002 -, foi possível dispor diretamente das informações sobre a produção e disseminação das estatísticas públicas da quase totalidade das unidades federadas (Quadro 1). Em dois casos, quando não se pôde obter a informação diretamente, optou-se por contatar um usuário qualificado (professor universitário ou técnico de planejamento do setor público) para preenchimento do questionário, ainda que em prejuízo de certo rigor metodológico na comparabilidade dos resultados. Por falhas na comunicação, encaminhamento institucional ou pelo fato da institucionalização do planejamento público desfrutar de menor prestígio ou organização, não se pôde dispor de informações específicas para quatro agências ou Secretarias Estaduais de Planejamento, correspondentes aos Estados do Maranhão, Piauí, Amazonas e Amapá.

\section{AS ESTATÍSTICAS PRODUZIDAS E COMPILADAS PELOS INSTITUTOS ESTADUAIS}

Um dos aspectos importantes que caracteriza a produção das agências estaduais é a natureza secundária dos dados estatísticos manipulados. De modo geral, as agências têm a incumbência de buscar informações produzidas nas diversas secretarias estaduais e compilá-las em um anuário ou compêndio de dados. É certamente uma função importante, necessária e mesmo estruturante das agências estaduais, que justifica sua existência e pode garantir sua perenidade institucional.

A produção primária de dados é antes uma exceção que uma regra (Tabela 1). Tal quadro naturalmente se justifica mais pela insuficiência de recursos financeiros e humanos das agências estaduais do que pela ausência de demanda de informações dessa natureza. Certamente as pesquisas da Fundação IBGE - como as PNADs (Pesquisa Nacional por Amostra de Domicílios) e Pesquisas Econômicas - cobrem boa parte dos interesses e necessidades de informação em nível agregado (estadual ou metropolitano, em alguns casos), mas evidentemente não respondem a questionamentos mais específicos temáticos e em termos de desagregação espacial requeridos pelos usuários dos sistemas estaduais de planejamento. Além disso, a inexistência de quadros técnicos com a expertise necessária para elaboração e condução de pesquisas primárias também deve ser um fator limitante para seu emprego mais generalizado.
Ainda assim, parece haver um esforço crescente de algumas instituições em coletar dados através de pesquisas diretas de campo, em domicílios ou estabelecimentos. Algumas delas - SEADE, Ipardes, SEI e FEE - têm pesquisas sobre a temática do trabalho e rendimento, com uma periodicidade mensal, e nas quais são encartados questionários suplementares para levantar temáticas de interesses específicos das secretarias estaduais. Outras iniciativas importantes são as relacionadas à produção própria de índices mensais de preços, custo de cesta básica ou acompanhamento conjuntural de setores econômicos (agricultura, comércio, construção civil, pequenas empresas) como a SEI, Seplan/AC, Ipardes, SEADE e Iplance. No caso do SEADE, realizam-se também outras pesquisas amostrais que cobrem temas socioeconômicos e econômicos mais gerais: a Pesquisa de Condições de Vida e a Pesquisa de Atividade Econômica Paulista.

Estruturadas para compilação de dados administrativos das secretarias e de outras pesquisas do IBGE, é natural que as informações sobre educação e saúde figurem entre aquelas mais regularmente manipuladas pelas agências estaduais. Afinal, essas áreas contam com sistemáticas de registro de informação mais antigas, criadas em função da necessidade de controle e planejamento do volume de recursos demandados no ensino fundamental e atenção básica à saúde pública. Dados provenientes do Registro Civil - compreendidos na temática população também estão entre os mais regularmente compilados pelas instituições. É digno de nota, inclusive, que dados acerca de projeções populacionais estejam sendo produzidos - primária ou secundariamente - por seis instituições estaduais, revelando o interesse crescente que dados de natureza prospectiva têm despertado no setor público, com a finalidade de subsidiar o planejamento.

Organizam e disponibilizam também outros dados de interesse ao planejamento público como os indicadores de finanças públicas, estatísticas de emprego formal, habitação e serviços urbanos, segurança pública e previdência, compiladas a partir de registros administrativos de órgãos públicos em diferentes níveis. Vale destacar a preocupação das agências com a compilação de dados sobre déficit habitacional, domicílios em favelas, trânsito, transporte urbano. Algumas agências também têm revelado preocupação em desenvolver indicadores específicos de monitoramento de políticas públicas e diagnóstico social, mais ou menos inspirados na proposta do Índice de Desenvolvimento Humano, como na FEE (Índice de Desenvolvimento Social Municipal Ampliado), Fundação João 
TABELA 1

Natureza da Coleta e Formatos de Disseminação da Informação Estatística, segundo Temas Brasil (1) - Dez./2001-Abr./2002

\begin{tabular}{|c|c|c|c|c|c|c|c|c|}
\hline Temas & $\begin{array}{l}\text { Coleta } \\
\text { Primária }\end{array}$ & $\begin{array}{c}\text { Coleta } \\
\text { Secundária }\end{array}$ & Site & Anuário & Boletim & Revista & CD-ROM & Outros \\
\hline \multicolumn{9}{|l|}{ POPULAÇÃO } \\
\hline Natalidade & 2 & 22 & 15 & 16 & 4 & 3 & 10 & 1 \\
\hline Mortalidade & 2 & 22 & 15 & 17 & 4 & 3 & 12 & 1 \\
\hline Óbitos fetais & 2 & 20 & 13 & 16 & 3 & 1 & 7 & 1 \\
\hline Outros eventos civis & 2 & 17 & 10 & 15 & 1 & 1 & 6 & 1 \\
\hline Projeção de população & 6 & 17 & 13 & 15 & 5 & 4 & 12 & 2 \\
\hline \multicolumn{9}{|l|}{ TRABALHO E RENDIMENTO } \\
\hline Desemprego & 5 & 12 & 8 & 7 & 8 & 2 & 6 & 2 \\
\hline Emprego formal & 3 & 16 & 11 & 11 & 9 & 4 & 8 & 2 \\
\hline Nível geral do salário & 4 & 14 & 11 & 11 & 8 & 3 & 5 & 2 \\
\hline Profissionais registrados em conselhos & - & 7 & 2 & 3 & 1 & - & 3 & - \\
\hline Estatísticas de sindicatos patronais/empregados & - & 2 & 2 & 2 & - & - & 1 & - \\
\hline Programa de formação profissional & - & 9 & 6 & 6 & 3 & 1 & 3 & - \\
\hline \multicolumn{9}{|l|}{ EDUCAÇÃO } \\
\hline Matrículas em ensino especial & - & 21 & 11 & 15 & 2 & 4 & 9 & 3 \\
\hline Matrículas em ensino pré-escolar & - & 23 & 12 & 17 & 3 & 3 & 11 & 3 \\
\hline Matrículas em ensino fundamental/médio & - & 23 & 12 & 17 & 3 & 3 & 11 & 3 \\
\hline Matrículas em ensino superior & 2 & 22 & 12 & 16 & 3 & 3 & 10 & 3 \\
\hline Indicadores de evasão/reprovação & - & 18 & 10 & 12 & 2 & 1 & 8 & 1 \\
\hline Número de professores/outros recursos humanos & - & 21 & 11 & 14 & 3 & 3 & 10 & 1 \\
\hline Número de escolas, salas, equipamentos & - & 20 & 12 & 14 & 2 & 3 & 9 & 1 \\
\hline Indicadores de desempenho escolar & - & 15 & 10 & 11 & 2 & 2 & 6 & 1 \\
\hline \multicolumn{9}{|l|}{ SAÚDE } \\
\hline Características dos recém-nascidos & - & 10 & 7 & 6 & 1 & 1 & 5 & - \\
\hline Estabelecimentos e equipamentos de saúde & - & 20 & 10 & 12 & 3 & 3 & 10 & 1 \\
\hline Estatísticas de vacinação & - & 19 & 8 & 12 & 3 & 2 & 7 & 1 \\
\hline Estatísticas de atendimento em saúde & - & 17 & 10 & 10 & 1 & 2 & 6 & - \\
\hline Estatísticas de mortalidade por causas & 1 & 19 & 11 & 10 & 2 & 2 & 9 & - \\
\hline \multicolumn{9}{|l|}{ HABITAÇÃO E SERVIÇOS URBANOS } \\
\hline Estimativa de domicilios situados em favela & - & 7 & 4 & 4 & - & - & 4 & 1 \\
\hline Déficit habitacional & 1 & 6 & 4 & 3 & 1 & - & 3 & 1 \\
\hline Abastecimento de água & 5 & 18 & 12 & 15 & 6 & 4 & 12 & 2 \\
\hline Esgotamento sanitário & 4 & 17 & 12 & 15 & 5 & 4 & 12 & 2 \\
\hline Limpeza pública & 2 & 12 & 6 & 8 & 3 & 1 & 5 & 2 \\
\hline Ligações em rede de energia elétrica & 3 & 18 & 12 & 13 & 5 & 3 & 10 & 2 \\
\hline Telefonia & 7 & 13 & 9 & 14 & 6 & 4 & 9 & 2 \\
\hline Trânsito & 1 & 17 & 10 & 10 & 3 & 2 & 6 & 1 \\
\hline Transporte urbano & 1 & 13 & 8 & 8 & 4 & 2 & 6 & 1 \\
\hline \multicolumn{9}{|l|}{ OUTROS INDICADORES SOCIAIS } \\
\hline Recursos humanos em segurança pública & 2 & 9 & 5 & 4 & 3 & 1 & 2 & 1 \\
\hline Ocorrências policiais & 2 & 17 & 9 & 11 & 3 & 1 & 6 & 1 \\
\hline Estatísticas judiciárias (julgamentos/prisões) & - & 11 & 7 & 6 & 3 & 1 & 3 & - \\
\hline Associativismo & - & 6 & 4 & 5 & - & - & 3 & - \\
\hline Estatística de previdência social & 1 & 17 & 9 & - & 1 & 1 & 5 & 1 \\
\hline Estabelecimentos culturais & 2 & 11 & 8 & - & 2 & 1 & 4 & - \\
\hline \multicolumn{9}{|l|}{ AGROPECUÁRIA } \\
\hline Produção de lavouras & 1 & 21 & 11 & - & 6 & 3 & 10 & 1 \\
\hline Produção animal & 1 & 21 & 11 & - & 6 & 3 & 10 & 1 \\
\hline Estimativa de safras agrícolas & 1 & 16 & 7 & - & 6 & 3 & 6 & 1 \\
\hline
\end{tabular}


TABELA 1

Natureza da Coleta e Formatos de Disseminação da Informação Estatística, segundo Temas Brasil (1) - Dez./2001-Abr./2002

\begin{tabular}{lcccccc}
\hline Temas & Coleta & Coleta & Site & Anuário & Boletim $\quad$ Revista & CD-ROM \\
\hline
\end{tabular}

\section{INDÚSTRIA}

Indicadores conjunturais da indústria

Produção, emprego, salário

Indústria e construção civil

Indústria mineral

COMÉRCIO E SERVIÇOS

Comércio atacadista

Comércio varejista

Estatísticas de turismo

Transporte de cargas

Transporte de passageiros

Estatísticas sobre empresas de serviços

Estatísticas sobre microempresas

Cooperativas

PREÇOS

Acompanhamento de preços no atacado

Índices ao consumidor

Cesta básica de consumo

CONTAS REGIONAIS

Estimativa de produto interno bruto - PIB

Projeção de PIB estadual

PIB municipal

Matriz de insumo-produto estadual

ADMINISTRAÇÃO PÚBLICA

Finanças públicas

Despesas públicas por função

Indicadores de monitoramento de políticas

GEOCIÊNCIAS

Cartografia

Imagem de satélite

Organização do território

Mapeamento temático

Mapeamento topográfico

RECURSOS NATURAIS E MEIO AMBIENTE

Energia

Climatologia

Conservação ambiental

Meteorologia

Poluição e degradação ambiental

\begin{tabular}{|c|c|c|c|c|c|c|c|}
\hline - & 15 & 3 & 10 & 3 & 2 & 5 & 3 \\
\hline- & 12 & 4 & 6 & 3 & 1 & 2 & 2 \\
\hline 3 & 12 & 5 & 6 & 3 & 2 & 4 & 3 \\
\hline- & 11 & 3 & 7 & 3 & 1 & 4 & 1 \\
\hline 1 & 10 & 2 & 3 & 1 & - & 2 & 2 \\
\hline
\end{tabular}

Fonte: Jannuzzi e Gracioso (2002)

(1) Excluem-se as agências estaduais de estatística dos Estados do Amazonas, Amapá, Maranhão e Piaui por não terem enviado o questionário. 
Pinheiro (Índice de Condições de Vida Municipal e o IDH - municipal, em parceria com o Ipea), SEADE (Índice Paulista de Responsabilidade Social), SEI (Índice de Desenvolvimento Social e Econômico Municipal), Cide (Índice de Qualidade dos Municípios - Carências), etc. Entre as estatísticas sociais não plenamente cobertas nos sistemas estaduais estão as estatísticas sobre associativismo, as informações provenientes de sindicatos, dados sobre consumo de serviços culturais, como conseqüência das dificuldades inerentes de coleta dessa informações e de sua confiabilidade. Também entram nesse conjunto as informações sobre meio ambiente, recursos naturais e cartografia, o que talvez se explique, por um lado, pela estrutura incipiente de secretarias e órgãos que tratam da questão em alguns Estados e, por outro, pela divisão efetiva das atribuições de produção, organização e disseminação desse tipo de informação em cada realidade estadual. ${ }^{4}$

As agências estaduais também parecem cumprir adequadamente sua função de coordenação do sistema estadual de estatísticas no que diz respeito às informações econômicas. Elas procuram disponibilizar através de suas publicações e outros meios as informações sobre desempenho conjuntural da indústria e comércio, produzidas em geral por sindicatos patronais. Parece haver uma crescente preocupação em produzir estimativas de PIB estadual e municipal, aprofundando, como é o caso da Fundação Cide e FEE, a elaboração de matrizes insumo - produto, recurso fundamental para estudos mais elaborados sobre a estrutura da economia estadual, suas interdependências com a dos demais Estados e para construção de cenários prospectivos do desenvolvimento econômico. Não figuram com mesma regularidade nos anuários estatísticos estaduais as informações sobre o setor serviços, microempresas e cooperativas.

\section{AS PRÁTICAS DE DISSEMINAÇÃO DA INFORMAÇÃO ESTATÍSTICA}

Até meados dos anos 90, o principal veículo empregado pelas agências estatísticas estaduais para disseminar as informações compiladas e produzidas era a publicação de Anuários Estatísticos. A cada ano os anuários eram ampliados em número de páginas, para atender às demandas específicas dos diversos usuários das informações e pelo esforço das agências em cobrir novas temáticas. De 200 a 300 páginas nas versões iniciais, os anuários estaduais rapidamente passaram para mais de 500 páginas nos anos seguintes. Além disso, de simples compêndio de dados, esses documentos passaram a incorporar algumas páginas com textos descrevendo as principais tendências observadas nas várias temáticas, além de gráficos, fotos e mapas. A partir de certo momento, os custos crescentes de produção acabaram por levar a um redimensionamento desses relatórios, em geral no sentido de limitar o detalhamento espacial das informações ou do próprio escopo temático coberto. $\mathrm{O}$ aparecimento da tecnologia do CD-ROM contornou tal problema e, em diversos casos, os anuários ganharam novo suporte físico, além do papel: o CD-ROM interativo. Sem dúvida, o advento do CDROM e o da Internet foram a tábua de salvação das agências estatísticas, ao permitir a disponibilização dos dados estatísticos em volume e rapidez jamais praticados, além de franquear ao usuário a possibilidade de produzir tabelas customizadas, adequadas às suas necessidades de detalhamento temático, temporal e espacial.

De fato, o que se pode verificar nos questionários respondidos (Tabela 1) é que a quantidade de informação disposta nos sites das instituições é igual ou até maior que a publicada nos anuários, que por sua vez, vale observar, não deixaram de existir nem de serem colocados dentre as prioridades editoriais das instituições. As informações coletadas quanto ao volume de consultas mensais aos $\mathrm{si}$ tes das instituições não parecem ainda adequadamente consistentes, mas apontam no sentido de utilização crescente. Na FEE houve cerca de 3.600 consultas ao mês em 2000 , aumentando expressivamente no ano passado (6.400 consultas/mês). No SEADE o movimento passou de 11 mil para 16 mil consultas/mês entre os dois anos.

Assim como aumentou o volume de consultas na Internet, também cresceu, de modo geral, a afluência de usuários às bibliotecas e centros de documentação das agências estaduais, em busca de informação estatística em diversas publicações impressas. Entre essas, as mais freqüentemente consultadas são os anuários do IBGE, anuários estatísticos estaduais, boletins e revistas produzidos pela instituição, e também livros, revistas e mapas, revelando o status de centro de referência qualificado de estudos das agências estaduais, além da possível inexistência de outras boas bibliotecas nas capitais estaduais (Tabela 2). Corrobora essa assertiva o fato de os usuários mais freqüentes das bibliotecas das agências serem alunos universitários, técnicos de secretarias estaduais e, em menor medida, jornalistas, técnicos de empresas privadas e alunos do ensino médio (Tabela 3). Chama a atenção, contudo, a reportada baixa freqüência de técnicos de ad- 
ministração municipal nos acervos das agências estaduais. Talvez isso se explique pelas barreiras físicas de distância e tempo dos municípios em relação às capitais, pelo uso mais freqüente dos anuários e da Internet. Mas pelo número de potenciais usuários seria de se esperar uma presença mais assídua desse tipo de usuário, assim como de membros de ONGs e de sindicatos.

No processo de disseminação da informação, as agências estaduais valem-se de profissionais de distintas áreas.

TABELA 2

Freqüência de Consultas ao Acervo da Instituição Brasil (1) - Dez./2001-Abr./2002

\begin{tabular}{lcccc}
\hline Publicações & Sempre & $\begin{array}{c}\text { Com Alguma } \\
\text { Freqüência }\end{array}$ & $\begin{array}{c}\text { Poucas } \\
\text { Vezes }\end{array}$ & Nunca \\
\hline Anuários estatísticos do IBGE & 18 & 4 & - & - \\
Anuários estatísticos da instituição & 18 & 3 & 1 & - \\
Boletins produzidos pela instituição & 20 & 3 & - & - \\
Revistas produzidas pela instituição & 10 & 3 & 2 & - \\
Livros & 13 & 6 & 1 & - \\
Revistas & 10 & 9 & 1 & - \\
Relatórios de pesquisa & 11 & 8 & 1 & - \\
Cartas, mapas, cartogramas & 8 & 4 & 6 & - \\
Compêndios & 3 & 5 & 7 & 1 \\
Normas & 2 & 4 & 10 & 1 \\
Guias e catálogos & 2 & 5 & 7 & 1 \\
Bibliografias & 2 & 5 & 7 & 1 \\
Documentos institucionais & 5 & 8 & 5 & 1 \\
\hline
\end{tabular}

Fonte: Jannuzzi e Gracioso (2002).

(1) Excluem-se as agências estaduais de estatística dos Estados do Amazonas, Amapá, Maranhão e Piauí por não terem enviado o questionário.

TABELA 3

Freqüência de Usuários à Instituição

Brasil (1) - Dez./2001-Abr./2002

\begin{tabular}{lcccc}
\hline Usuário & Sempre & $\begin{array}{c}\text { Com Alguma } \\
\text { Freqüência }\end{array}$ & $\begin{array}{c}\text { Poucas } \\
\text { vezes }\end{array}$ & Nunca \\
\hline Administração municipal & 9 & 8 & 5 & 1 \\
Secretarias e órgãos estaduais & 17 & 6 & - & - \\
Público universitário & 22 & - & - & - \\
Alunos de ensino médio & 8 & 12 & 2 & - \\
Alunos de ensino fundamental & 3 & 10 & 7 & 2 \\
Jornalistas (ainda que por telefone) & 8 & 13 & 2 & - \\
Membros de associações patronais & 3 & 4 & 13 & 2 \\
Membros de sindicatos & 2 & 7 & 12 & 2 \\
Membros de ONGs & 2 & 10 & 9 & 1 \\
Funcionários de empresas em geral & 8 & 9 & 5 & 1 \\
Func. de empresas de consultoria & 12 & 7 & 3 & - \\
\hline
\end{tabular}

Fonte: Jannuzzi e Gracioso (2002).

(1) Excluem-se as agências estaduais de estatistica dos Estados do Amazonas, Amapá, Maranhão e Piauí por não terem enviado o questionário.
Dentre as 23 agências estaduais estatísticas analisadas, bibliotecários, profissionais de informática e auxiliares de biblioteca estão presentes na maioria delas. Os estagiários, analistas e profissionais advindos de outras áreas também participam com intensidade significante, embora menor, diante da Disseminação de Informações nas agências estaduais. Entretanto, são os profissionais de informática que se concentram em maior número no conjunto de todas as agências analisadas, seguidos por estagiários e auxiliares de biblioteca, sendo relativamente baixo o número de bibliotecários envolvidos com a Disseminação da Informação. É relevante considerar que seria conveniente os profissionais envolvidos nesse serviço possuírem competências para lidar com Tecnologias da Informação e condições de analisar e avaliar demandas informacionais, visando a adequação dos produtos para atendê-las. Ainda seria válido que esse profissional conhecesse os procedimentos relacionados ao tratamento temático e descritivo da informação a fim de tornar ágil sua disseminação e recuperação.

A julgar pela declaração prestada pelas agências estaduais de estatística, as políticas e práticas de disseminação de informações são bastante satisfatórias (Tabela 4). A maioria das agências declarou distribuir produtos gratuitamente às bibliotecas e órgãos públicos, ter contatos regulares com a imprensa e com técnicos de planejamento. A comunicação com a comunidade científica também é apontada como prática corrente de várias agências esta-

TABELA 4

Práticas e Políticas de Disseminação da Informação Estatística Brasil (1) - Dez./2001-Abr./2002

\begin{tabular}{lc}
\hline Práticas e Políticas de Disseminação & Total de \\
& Agências \\
\hline
\end{tabular}

Venda de produtos a preços subsidiados ao público em geral 9

Venda de produtos a preços com desconto a órgãos públicos 5

Distribuição gratuita de produtos para órgãos estaduais e municipais 21

Distribuição gratuita de produtos para bibliotecas públicas 21

Distribuição gratuita de produtos para bibliotecas escolares 13

Distribuição gratuita de produtos para bibliotecas universitárias 20

Reuniões e entrevistas regulares com a imprensa 13

Reuniões e entrevistas regulares com órgãos públicos 13

Seminários de capacitação a jornalistas e outros profissionais 2

Seminários de capacitação a técnicos do setor público 10

Apresentação de resultados de pesquisa em

conferências, seminários e workshops

14

Fonte: Jannuzzi e Gracioso (2002).

(1) Excluem-se as agências estaduais de estatística dos Estados do Amazonas, Amapá, Maranhão e Piauí por não terem enviado o questionário. 
duais, pela participação em eventos acadêmico-profissionais. Contudo, a venda a preços subsidiados das publicações - prática desejável se se considerarem os benefícios concretos e os incomensuráveis do uso da informação estatística nas atividades do setor acadêmico, público e privado - é uma prática pouco usual. As restrições orçamentárias das agências certamente as obrigam a encarar a venda de produtos como uma das poucas estratégias para desenvolver recursos próprios ou mesmo para desoneração de suas despesas operacionais.

Um aspecto a valorizar nas estratégias de disseminação de informações são as iniciativas do IBGE e de algumas agências estaduais como a SEI e a FJP em organizar cursos de capacitação e atualização de jornalistas e profissionais de comunicação social. As especificidades da informação estatística também deveriam mobilizar um maior número de agências a organizar seminários de capacitação de técnicos municipais de planejamento. A demanda para isso certamente existe na maioria dos Estados, de norte a sul do país, como mostram as iniciativas da Cide, Iplance, Seplad/RO, Sepan/AC, Seduh/DF, Sepan/ MT, FEE e FJP.

\section{CONCLUSÃO}

O Sistema de Informações Estatísticas brasileiro encontra-se em um ponto de inflexão de sua trajetória histórica, como tantos sistemas congêneres em âmbito internacional (Thygesen, 1994). Um grande esforço foi realizado nos últimos 30 anos para ampliar o escopo temático coberto pelas pesquisas e também para torná-las acessíveis aos seus principais usuários na Administração Pública.

Contudo, as novas demandas de informação estatística, em escala geográfica mais detalhada e mais periodicamente atualizada, produtos mais específicos, acesso mais amplo às bases de dados governamentais impõem novos esforços e desafios às agências estatísticas, sejam financeiros, sejam organizacionais, sejam tecnológicos.

Pelo que se pôde avaliar por esse levantamento em agências estaduais, a disseminação de informação estatística está passando por uma grande mudança nos últimos anos, em função das demandas da sociedade, das necessidades de informação para o planejamento público e das facilidades e desintermediação que as novas tecnologias de informação estão criando.

Este relatório é um primeiro diagnóstico do "estado da técnica" da produção e das práticas de disseminação da informação estatística. Sem dúvida, é necessário apro- fundar o entendimento de algumas das questões aqui colocadas através de levantamentos de natureza mais qualitativa, com a realização de entrevistas com dirigentes, técnicos e usuários de agências estaduais.

Em uma perspectiva mais abrangente seria possível pensar em um projeto de Análise Institucional comparada das agências estaduais, levantando formas de organização administrativa, perfil do quadro técnico, custos de produção da informação e avaliação dos benefícios tangíveis e intangíveis do uso dos dados estatísticos. Ganhariam todos, sociedade, empresas, administração pública e os institutos de planejamento e estatística. Estes últimos poderiam mostrar que o gasto monetário per capita envolvido na manutenção de suas estruturas de pessoal e de pesquisas está, como se supõe, aquém do praticado em outros países de dimensão populacional, de produto econômico ou extensão territorial como o Brasil.

\section{NOTAS}

A realização deste trabalho foi possível graças ao apoio institucional concedido pela Ceap/PUC-Campinas, à colaboração voluntária de diversos técnicos das agências estaduais de pesquisa no preenchimento dos formulários e ao incentivo e iniciativas do sr. César Vaz, superintendente da SEI/BA, e do sr. Waldir Peres, diretor científico da Cide, que garantiram a possibilidade de exposição da pesquisa no Encontro da Anipes realizado em novembro de 2001 no Rio de Janeiro. As interpretações, opiniões, faltas e omissões aqui apresentadas são de exclusiva responsabilidade dos autores.

1. O projeto inclui ainda a realização de entrevistas com sujeitos qualificados da área: dirigentes de agências estatísticas, especialistas nos campos da produção, disseminação e/ou uso da informação estatística, técnicos de planejamento do setor público, dirigentes e gestores de programas públicos na área social em diferentes esferas de governo. Através de entrevistas com roteiros semi-estruturados busca-se complementar o quadro descritivo e explicativo para a situação identificada no levantamento estruturado anteriormente descrito.

2. Contou-se, nesta etapa da pesquisa, com a colaboração da bolsista Maria Júlia Guimarães (Pibic/CNPq).

3. Sucintamente, o Tesauro é um instrumento de controle terminológico em que termos são estruturados e relacionados semântica e hierarquicamente visando facilitar processos de tratamento e recuperação de informações sobre determinada área do conhecimento.

4. Seria interessante, no âmbito da Anipes, fazer um levantamento complementar para identificar os órgãos estaduais que tratam da Informação Cartográfica, assim como as agências centralizadoras de informação sobre Ciência e Tecnologia.

\section{REFERÊNCIAS BIBLIOGRÁFICAS}

ALLEVATO, S.R. "Metodologia de inventário das estatísticas nacionais para o Mercosul". Ciência da Informação. v.24, n.2, 1995. (Comunicações). 
ANIPES - ASSOCIAÇÃO NACIONAL DAS INSTITUIÇÕES DE PLANEJAMENTO, PESQUISA E ESTATÍSTICA. Sistema de informações das instituições públicas de pesquisa, em nível nacional. Curitiba. Disponível em: <http://www.ipardes.gov.br/anipes $>$. Acesso em 24/01/01.

GRACIOSO, L. de S. e JANNUZZI, P.M. "Informação estatística brasileira: proposta de controle de vocabulário para a disseminação". Congresso Brasileiro de Biblioteconomia, Documentação e Ciência da Informação. Fortaleza. Anais... Fortaleza, 2002.

GUIZZARDI, F.O. e CONTI, V. "Produção e disseminação de informações socioeconômicas". Transinformação. Campinas, v.13, n.2, 2001, p.43-54.

IBGE. Estatísticas e indicadores sociais para a década de 90. Rio de Janeiro, IBGE, 1989.

. Catálogo do IBGE. Rio de Janeiro, IBGE, 2000.

JANNUZZI, P.M. "Fontes de informação sociodemográfica para planejamento no setor público". Revista de Administração Pública. Rio de Janeiro, v.29, n.3, 1995, p.197-210.

. "Novas e velhas demandas de informação estatística". São Paulo em Perspectiva. São Paulo, Fundação Seade, v.12, n.4, 1998, p.105-12.

. Indicadores sociais no Brasil: conceitos, fontes de dados e aplicações. Campinas, Alínea, 2001.

JANNUZZI, P.M. e GRACIOSO, L. de S. Levantamento da produção $e$ disseminação da informação estatística no Brasil. Campinas, PUC-Campinas, 2002 (Relatório de Pesquisa).
MINISTÉRIO DA CIÊNCIA E TECNOLOGIA (MCT). Sociedade da informação no Brasil - Livro Verde. Brasília, 2000.

NAÇÕES UNIDAS. Handbook of social indicators. Nova York, 1988.

PROSÉRPIO, R. "Repartição de encargos governamentais: a função de informar". São Paulo em Perspectiva. São Paulo, Fundação Seade, v.8, n.4, 1994, p.75-81.

SENRA, N.C. "Por uma disseminação democrática de informações". São Paulo em Perspectiva. São Paulo, Fundação Seade, v.8, n.4, 1994, p.40-5.

. A coordenação da estatística nacional: o equilibrio entre o desejável e o possivel. Tese de Doutorado em Ciência da Informação. Rio de Janeiro, Universidade Federal do Rio de Janeiro, 1998.

THYGESEN, L. "Comercializando estatísticas oficiais sem vender a alma". São Paulo em Perspectiva. São Paulo, Fundação Seade, v.8, n.4, 1994, p.68-74.

Paulo de Martino Jannuzzi: Professor da PUC-Campinas e da ENCE-IBGE (pjannuzzi@mpc.com.br).

Luciana de Souza Gracioso: Mestranda em Biblioteconomia e Ciência da Informaçãona PUC-Campinas (lugracioso@yahoo.com.br). 